\title{
The Influence of Structural Social Capital on Performance of Social Enterprises in Nairobi City County, Kenya
}

\author{
Lucy Kibe Wairimu \\ School of Business and Economics, Mount Kenya University, Kenya
}

\begin{abstract}
Social capital is becoming an increasingly subtle part of achieving social economic goals especially in grassroots of a developing country. Kenya is in an infantile state of appreciating social capital as a panacea for economic growth albeit the developing economic status of the country. The study focused on examining the influence of structural social capital on the performance of social enterprises in Nairobi city county, Kenya. Mixed methodology was applied in the study that also adopted a descriptive cross sectional survey design. The target population was 300 composed of registered social enterprises in Nairobi County. 107 social enterprises were selected through simple random sampling. Self administered, semi- structured questionnaire was administered. The reliability of the research tool was established through a pilot test retest procedure, whose cronbanch alpha was established to be above 0.7. Descriptive and inferential statistics methods were adopted for data analysis. Hypothesis was tested using ANOVA. To test for statistical significance of the relationship of the variables Pearson's moment correlation and chi-square were used. The regression analysis for structural social capital on performance yielded regression coefficient of $0.262, p=0.049<0.05$. This implies that the Structural Social Capital have positive influence on Performance of Social Enterprise that is statistically significant at $5 \%$. $\mathrm{H}_{0}=$ Structural social capital does not influence social enterprise performance was rejected.
\end{abstract}

Keywords: Structural social capital, Social enterprise, Performance, Social transactions, Embeddedness

DOI: $10.7176 / \mathrm{EJBM} / 11-7-11$

Publication date:March $31^{\text {st }} 2019$

\subsection{Introduction}

Structural social capital is defined as the institutional capital involving the networks ties and the configuration from which other forms of capital are established (Krishna, 2000; Gooderharm,Paul N, 2007). Structural social capital represents the existence of networks that facilitate connections to people and acquisition of resources (Andrews, Rhys, 2010). It is evident that social capital is great contributor of the welfare of members of community. It has far reaching effects on health, wellbeing, wealth and also success of the day today activities by both formal and informal groups or associations including work place in the community.

According to Coleman, 1990 social capital comprises of interrelationships within individuals and institutions with the aim of attaining goals that would otherwise not be attained while supporting this argument. Stone and Hughs, (2002) proposed that social capital has the elements of networks, reciprocity and trust. The social structure perspective in which structural social capital is based has its foundations on the historic work of Grannovetter,(1992) on embeddedness of structural and relational social capital. (Nahapiet. J \& Sumantra ghoshal,1998) differentiates social capital types on the basis of ties, quality of the networks and intensity of shared vision. According to the authors structural social capital is highly associated with the network ties and the composition, roles and procedures and the outcomes. Social capital therefore comprises a form of social structure with social relationships and norms. Thus Structural social capital has a structural angle visibly identifiable in the existence of network ties within a formal structure with explicit roles and procedure to enable resource acquisition and interactions. The structural social capital accord a formalized structure relevant for the affiliated social transactions.

Structural social capital reflects the network between a community and groups in a community with vertical institutions. This form of capital has a Linking aspect of the vertical connections that connect the basic individual groups with institutions (World Bank, 2002). It is vertical by nature as the different institutions influence policies or resources acquisition (Pretty, 2003). Structural social capital involves vertical interactions with individuals who are influential in positions of political or financial power and whose linkages are critical for leveraging resources (Côté \& Healy, 2001; Woolcock, 2001). Through institutional ties that may be pre existing or are developed, social entrepreneurs access the most needed resources inclusive of information, ideas, commercial opportunities, financial capital, power and influence, emotional supports and even goodwill, confidence and cooperation which blend together to create success of an enterprise from formal institutions and which are beyond the local community horizontal networks. The degree to which social capital is beneficial depends on how well structural capital in terms of linkages between members of community and formal institutions, are utilized by members of the community (World Bank, 2002; Grootaert, 2003). Economic development is fostered in an environment where social capital in form of trust and cooperation exists in the firm, industry, market and the state. The tenacity of social bonds generated by social cohesion and inclusion, empowerment and political goodwill, which are strategic 
social capital tools, are influential in determining inclusion or exclusion of community members. According to World Bank, (2002a), while Cohesion can be demonstrated through community events or through activities that increase solidarity, strengthen interactions, improve communication for coordinated activities, promote civicmindedness and altruistic behaviour, and develop a sense of collective consciousness, empowerment displays how Individuals legitimacy have a measure of control over the institutions and processes that directly affect their wellbeing. Structural social capital dimension of empowerment is a an aggregate of satisfaction, personal efficacy, and capacity of network and group members coupled with ability to influence both local events and broader political outcomes .The study seeks to explore whether structural social capital is applied and the extent to which it influences performance of the social enterprises.

\subsection{Literature Review}

\subsection{Social Capital Theory}

The theoretical review is based on social capital theory by Putnam (1993). In an early definition social capital was identified with those features of social organization, such as trust, norms, and networks that scale the efficiency of society activities by facilitating coordinated actions". According to this theory voluntary associations across individuals in networks enable a horizontal linking which produce trust, a norm that produces interpersonal bonding. This trust leads to reciprocity which is an essential component of social capital and which increases with use and decreases with disuse. Social capital embodies the coordination and cooperation for mutual benefits in organizational setup and which extends to the larger community. Later while in the article "bowling alone" Putnam (2000), proposed that social capital is a universal lubricant of social relations by which functioning of modern communities operate. Coleman,(1995) on the other hand emphasizes that social capital resides in social structure that is embedded among the networks(individuals and groups)

Bourdieu, 1986 theory of social capital asserts that power and status led to the evil in social capital which is uneven distribution of social capital between individuals. From social interactions social networks,norm of reciprocity and trustworthiness The social capital plays the role of expanding and increasing cohesion amongst the players in a group, which results from individuals' interconnections, social networks and the norms of reciprocity and trustworthiness that arise from them. He emphasizes that institutions are generated and sustained by beliefs members have about one another and the rest of the world. The beliefs or faith is the core link between social capital and institutions. Economic agents are able to realize benefits by virtue of participation in social networks and structures available in the community. The theoretical proposition shows there exists a positive association between social ties, within individuals, groups (elements of social capital) and institutions.

According to Nahapiet \& Ghosal, (1998) Structural aspect focuses on the number or amount of direct and indirect networks. Structural Social capital is also defined in terms of external linkages. The linking social capital symbolizes the network between a community or groups in a community with institutions and groups of higher order and is therefore associated with structural social capital

Social capital value is dependent on the type of activities that members of the web engage in (Dasgupta, 2005). Accordingly Dasgupta, (2005) explains that social capital has potential to stimulate viable economic opportunities through the system of interpersonal networks which enhances cooperation and collaboration. From social entrepreneurial perspective social capital is viewed as network, group ties and institutions that support social entrepreneurial activity and the level of perceived benefits and resources available from social ties (Ernst, 2012, Narayan \& Pritchett, 1997).The extent to which the forms of social capital benefits the society is dependent upon active engagement by members of the community (Ernst, 2012; Basu, 2012). The social enterprise benefits accrued are dependent on utilization of structural social capital. Increased social capital is likely to scale risk sharing potential of members as they provide an informal safety net. Studies have shown that social capital is a strong and consistent asset especially during initial stages of business creation and among micro and small enterprises. Social capital is viewed as an enabler as it is used as a source of information, frame of reference, access to resources, source of potential suppliers and customers among others.. The factors form the basis for conceptualizing how the relational social capital may influence the activities in the social enterprises that lead to success or performance of the social enterprises,

Conceptually its evident that structural social capital in form of the institutional ties and empowerment aspect of individuals in position of authority in which resources are controlled and or distributed influence the success of enterprise in as far as the productivity, sustainability and scaling up or growth is achieved.

\subsection{Empirical Literature Review}

According to Côté and Healy (2001); Woolcock (2001) this stratified form of social capital involves vertical interactions with individuals who are influential in positions of political or financial power and whose linkages are critical for leveraging resources. Through institutional ties that may be pre existing or are developed, social entrepreneurs access the most needed resources inclusive of information, ideas, commercial opportunities, financial capital, power and influence, emotional supports and even goodwill, confidence and cooperation which 
blend together to create success of an enterprise from formal institutions and which are beyond the local community horizontal networks .

Olabisi, (2013) used social action theory to examine how Yoruba women textile traders sought for and access resources. It was established that women engage multiple avenues within their social systems to source finance and generate income. It was also showed that women's collective approach and action have an impact on entrepreneurial development of the society.

Datta, (2012) case studied the extent to which social inclusion and empowerment breed entrepreneurial activity among women in India. The study found out that collective approach to entrepreneurial action empowers women through advancing their economic security, entrepreneurial behaviour and increasing their income contribution in the family.

Karimzadeh, Majid, Faraz Ahmad, Bahman Karimzadeh(2013), in a research on Impact of Social Capital on Quality of Life conducted in India, where a survey was conducted in different households the results indicated a positive correlation between social capital and quality of life, accordingly social capital insinuate the magnitude communities provide members with openings by offering supportive relationship, crosscutting involvement of communal activities to increase their intergraded wealth.

According to Ali, Saeid and Mohsen (2012) Social capital is a modern concept that is used extensively nowadays in sociology, economy and recently in management and organization. It refers the existing resources inside and among the personal and commercial network. These resources include information, ideas, commercial opportunities, financial capital, power and influence, emotional support, goodwill, confidence and cooperation which blend together to create success of an enterprise.

In a research conducted by Tehran and Delhi by Ounagh and Ounagh, (2011) on relationship between social capital and quality of life Regression results indicated a correlation between social capital and quality of life. It was also found that the indicators communication, locality, social participation, social trust, and local solidarity were predictor on quality of life in Delhi whereas in Tehran where communication was not

According to a survey by Allahdadi (2011) on "Building Social Capital for Poverty Reduction in Rural Areas of Marvdasht, Iran" in 250 households results revealed that social capital is instrumental in poverty reduction. However, communication and social cohesion had a greater impact than other social capital indicators; the collaboration, network empowerment and trustworthiness. For successful poverty reduction the rural people should collaborate with the government organizations. This will create inclusivity in decision making process which affects their lives and communities. In order to mitigate the exclusion the policies made by central government should aim at promoting and stimulating social capital investment for rural development and poverty reduction.

\subsection{Critique of existing literature}

Social capital is evidently an important aspect of survival for social enterprises. Fukuyama (1995) proposes that interpersonal trust is critical for social relationship to thrive and influence economic growth. Where mutual trust is enjoyed transactional costs are low and therefore the cost of business and the likely profitability. It enhances collaboration, mutual support due to the shared norms and values. Where trust thrives reciprocity is enjoyed and this will have a positive impact in the social enterprises performance in terms of acceptability of goods and services. Social capital therefore is about ability to access the existing resources inside and among the personal and commercial network. These resources include information, ideas, commercial opportunities, financial capital, power and influence, emotional supports and even goodwill, confidence and cooperation which blend together to create success of an enterprise.

Social capital does not depreciate like other forms of capital with utilization, the more it's utilized the higher the value increases. While physical capital exhausts with use, social capital scales with use. Where social capital application is recognized there is likelihood of significant correlation with organizational growth. A number of other authors in the literature, such as Putnam et al. (1993), and Narayan \& Cassidy (2001), reiterate presence of social capital is dependent on how extensively it's mutually utilized. In conclusion, to create social capital one must invest time and resources to sustain social interactions. Social capital is a critical factor that explains economic growth. The marginal productivity of social capital, is positive and thereby it has definite returns or/and incentives to grow by widening social network.

Government officials and public policy makers should foster adoption of structural social capital by institutionalizing its influence towards successful implementation of economic goals which will consequently contribute to developing a good and professional social entrepreneurship Development of networks among individuals, groups and institutions will scale the level of social trust, the collateral that will solve the problems of poor people collectively. From the Theoretical and empirical literature underpinnings social entrepreneurships is a hybrid that adopts economic models to pursue social objectives. The organizations adopt market based methods of income generation to pursue social objective in an aim to sustainably improve the status quo in the society. Theoretical literature revealed structural social capital facilitate vertical network associations which are used to expand the market and source information and resources needed to meet social enterprises objectives. Empirical 
review especially in Africa suggests that social enterprises play a critical role in the grassroots organizations. Evidence of social entrepreneurship factors' role among social suggests that social networks innovatively stimulate growth of grassroots organization and social enterprises in general. Social entrepreneurship is critical for economic development as it creates social value through employment development for the disadvantaged in the society, initiates innovations in new products and services to fulfill unmet social needs, introduces the much needed social capital as a resource linked to possession of networks and ties which are critical to the sustainability of economic development and lastly, equity promotion for addressing social deficits and ensuring sustainable impact through social mission activities that are not addressed by existing economic mainstream (Jurgen, 2007).

The following study was carried out on the determinants of the performance of social enterprises in Nairobi city county Kenya

\subsection{Results and discussions \\ 3.1 Response Rate}

The data was collected from the social enterprise management representatives in Nairobi County, Kenya which are registered with East African Social Enterprises network (EASEN). The sample of the study consisted of 107 respondents. A total of self administered 98 questionnaires were filled out of the 107 yielding a response rate of $91.6 \%$ as displayed on Table1. According to (Babbie, 1995) the response of $80 \%$ is sufficient for the study, indeed 70 percent response rate and above to be very good. Bailey, (1994) suggests that the adequacy rate is $75 \%$. This insinuates that based on the above argument the response rate is very good.

Table1 : Response rate

\begin{tabular}{lll}
\hline Items & Respondents & Response Rate \\
\hline Filled questionnaires & 98 & $91.6 \%$ \\
Non Filled questionnaires & 9 & $8.4 \%$ \\
Total & 107 & 100 \\
\hline
\end{tabular}

\subsection{Descriptive analysis of structural social capital on the performance of social enterprises.}

This section discusses descriptive statistics of the study variable on influence of structural social capital on the performance of social enterprises in nairobi county kenya. the test for normality was first presented then the empirical data on respondents and the qualititive data followed by discussion and content analysis.

\subsection{Diagnostics Test for Structural Social Capital}

The researcher sought to test suitability of the data collected(Table 2) for structural social capital among the social enterprises in Nairobi City County, Kenya. This was done by testing whether the data was normally distributed by performing Kolmogorov-Smirnov Test.

Table 2:

Diagnostic test for structural social capital.

\begin{tabular}{lll}
\hline & Structural Social Capital & \\
\hline & $\mathrm{N}$ & 92 \\
Normal Parameters $^{\mathrm{a}, \mathrm{b}}$ & $\mathrm{Mean}$ & 3.75 \\
& Std. Deviation & 0.807 \\
\hline Most Extreme Differences & Absolute & 0.263 \\
& Positive & 0.215 \\
& Negative & -0.263 \\
\hline Kolmogorov-Smirnov Z-value & & 2.522 \\
\hline $\boldsymbol{p}$-value & & 0.000 \\
\hline
\end{tabular}

Kolmogorov-Smirnov Test for Structural Social Capital

The results as represented in Table 2 indicate that the Kolmogorov-Smirnov Z-value for structural social capital was 2.522 with a $p$-value of $0.000<0.05$ which signifies that the variable structural social capital data that was collected is normally distributed. This shows the data as presented is suitable for further analysis.

\subsection{Respondents Opinions towards Structural Social Capital}

In an attempt to examine extent of structural social capital manifested by social enterprises in Nairobi City County, Kenya, the response categories (Table 3) were structured into a five Likert Scale measure comprising of; Not at All, Small Extent, Moderate Extent, Large Extent and Very Large Extent. 
Table 3: Extent of agreement on statements regarding Structural Social Capital for Social Enterprises

\begin{tabular}{llllll}
\hline Statements & Percent & & & \\
\cline { 2 - 5 } & $\begin{array}{l}\text { Not } \\
\text { at All }\end{array}$ & $\begin{array}{l}\text { Small } \\
\text { Extent }\end{array}$ & $\begin{array}{l}\text { Moderate } \\
\text { Extent }\end{array}$ & $\begin{array}{l}\text { Large } \\
\text { Extent }\end{array}$ & $\begin{array}{l}\text { Very } \\
\text { Large } \\
\text { Extent }\end{array}$ \\
\hline $\begin{array}{l}\text { Access to information related to education and } \\
\text { training facilities }\end{array}$ & 4.4 & 17.6 & 23.1 & 26.4 & 28.6 \\
$\begin{array}{l}\text { Access to health services, water supply, waste } \\
\text { management etc }\end{array}$ & 8.7 & 10.9 & 15.2 & 34.8 & 30.4 \\
$\begin{array}{l}\text { Helps in seeking information and access to } \\
\text { business loans }\end{array}$ & 3.3 & 6.5 & 32.6 & 29.3 & 28.3 \\
$\begin{array}{l}\text { Availability of advice from formal institutions } \\
\text { (Banks, credit Sacco's, Government) }\end{array}$ & 5.4 & 10.9 & 19.6 & 40.2 & 23.9 \\
$\begin{array}{l}\text { Helps in soliciting help from government } \\
\text { officials NGOs and politicians. }\end{array}$ & 4.4 & 12.1 & 19.8 & 34.1 & 29.7 \\
$\begin{array}{l}\text { Helps in access to information about current } \\
\text { government and non-governmental programs } \\
\text { that may be beneficial to our community }\end{array}$ & 4.4 & 6.7 & 16.7 & 38.9 & 33.3 \\
$\begin{array}{l}\text { Enables the establishment and accessibility of } \\
\text { linkages for markets }\end{array}$ & 6.7 & 9.0 & 34.8 & 29.2 & 20.2 \\
$\begin{array}{l}\text { Through the potential linkages, customers and } \\
\text { suppliers are easily acquired. }\end{array}$ & 3.4 & 10.1 & 14.6 & 43.8 & 28.1
\end{tabular}

From the study, it was established that majority of the respondents (55.0\%) believes that through social enterprises, it is easier to access information related to education and training facilities. Majority, $65.2 \%$, pointed out that they help in accessing health services, water supply and waste management among other important services to members. Similarly, $57.6 \%$ indicated that through social enterprises, it becomes easier to seek information and access to business loans thus enhances the potential of doing business among members. The results agree that linking social capital is the vertical connections that connect the basic individual groups with institutions (World Bank,2002). The degree to which social capital is beneficial depends on how well structural capital in terms of linking social capital is exploited. From social entrepreneurial perspective social capital is viewed as network, group ties and institutions that support social entrepreneurial activity and the level of perceived benefits and resources available from social ties (Ernst, 2012).

The coming together was considered to be of great importance by majority, at $64.1 \%$, since it makes available adequate advice from formal institutions that include Banks, credit Sacco's, and Government. They also help in soliciting help from government officials NGOs and politicians as it was stated by $63.8 \%$. The findings also subscribes to the study by Côté, and Healy (2001), Woolcock (2001), Pretty (2003) which found that social capital involves vertical interactions with individuals who are influential in positions in institutions of political or financial power and whose linkages are critical for leveraging resources accessing most needed ideas, policies from formal institutions and which are beyond the local community horizontal networks. As the majority (72.2\%) indicated, social enterprises help in access to information about current government and non-governmental programs that may be beneficial to our community. The networking established by the enterprises, enable the establishment and accessibility of linkages for markets according to $49.4 \%$ of the respondents. Through the potential linkages, $71.9 \%$ argued that customers and suppliers are easily acquired. This collates with Ernst, 2012 that structural social capital in which network ties are beneficial to the social enterprise.

\subsection{Institutional Support Strength and Viability}

The researcher asked the respondents to comment on the strength of institutional support accessed by the social enterprise using an open ended question whose response was analysed using content analysis. The social capital support was considered to be in the form of information acquisition, partnership and financing. The findings indicates that $76.92 \%$ of respondents considered the support to be high while $23.07 \%$ found it to be moderate. As for the viability of the support, $86.67 \%$ considered the support to be highly viable while $13.33 \%$ stated that it was moderately viable. This shows that the social enterprises are adequately supported in terms of information, partnership and was financing which is key and relevant resource toward achieving the social economic goals of the social enterprise.

\subsection{Inferential statistics analysis}

Hypothesis testing for the Entrepreneurial Determinant influence on the Performance of Social Enterprises. H0: structural social capital has no significant influence on the performance of social enterprises in Nairobi City County, Kenya. 
The researcher conducted inferential statistical to test hypothesis (Triola, 2008) that comprised of Pearson Correlation of coefficient, Multiple Regression and Chi-square.

A correlation exists between two variables when one of them is related to the other in some way (Triola, 2008). Where more than one independent variables exists in the study multiple regression models are used (Lind et al, 2008). Chi-square statistics is also used for confirming whether a variable in a sample represents the actual relationship between the variables under observation. Therefore the three statistics were conducted to proof the existence of a relationship nature of the relationship and the extent of the relationship between the Entrepreneurial Determinants and the Performance of Social enterprises

\subsection{Regression Analysis of Performance of Social Enterprise on the structural social capital}

The researcher conducted further regression analysis to explain the influence of Structural Social Capital (SSC) on Performance of Social Enterprise (PSE).

First the data was tested to determine its suitability of the data for regression analysis as explained by the regression ANOVA. The data should be accurate complete and suitable for further analysis (Sekeran \& Bougie, 2010).

Table 4: Regression ANOVA

\begin{tabular}{llllll}
\hline & Sum of Squares & df & Mean Square & F & p-value \\
\hline Regression & 41.265 & 6 & 6.878 & 11.295 & $.000^{\mathrm{b}}$ \\
Residual & 49.93 & 82 & 0.609 & & \\
Total & 91.195 & 88 & & & \\
\hline
\end{tabular}

a Dependent Variable: PSE

b Predictor: (Constant), SSC

Since the $\mathrm{p}$-value $=0.000<0.05$ as shown in the Regression ANOVA results, this implies that regression analysis is statistically significant at 5\% levels of significance and therefore applicable for the study.

Table 5: Regression analysis of social enterprise performance on structural social capital

\begin{tabular}{llllll}
\hline & & Standardized & Coefficients & \\
& Unstandardized Coefficients $(\mathbf{B})$ & Std. Error & $(\boldsymbol{\beta})$ & $\mathrm{t}$ & $\boldsymbol{p}$-value \\
\hline (Constant) & -0.258 & 0.686 & & -0.376 & 0.708 \\
SSC & 0.262 & 0.132 & 0.208 & 1.993 & 0.045 \\
\hline
\end{tabular}

a Dependent Variable: PSE

The regression analysis for structural social capital on social enterprise performance yielded a regression coefficient of $0.262, p=0.045<0.05$. This implies that the Structural Social Capital has a positive influence on Performance of Social Enterprise and is statistically significant at 5\% levels of significance.

For Structural Social Capital, the coefficient of regression was 0.262, at $\mathrm{p}$ value $=0.045$. This implies that structural social capital was statistically significant $(\mathrm{p}=0.045<0.05, \mathrm{~B}=0.262)$. This implies that for a point increase in structural social capital the performance of social enterprises has an increase of $26 \%$; holding all other factors constant. Therefore the relational social capital has a moderate positive influence on social enterprise performance. $\mathrm{PSE}=\mathbf{- 0 . 2 5 8}+\mathbf{0 . 2 6 2} \mathrm{SSC}$ Equation 1

\subsection{Karl Pearson Correlation Analysis}

The researcher used Karl Pearson Correlation analysis (Table 6) to test the relationships between the following study variable; Performance of Social Enterprise (PSE) and Structural Social Capital (SSC), the nature of the relationship is determined by the coefficient of correlation while the significance of the relationship at $5 \%$ levels of significance is explained by the p-value.

Table 6: Karl Pearson Correlation of Entrepreneurial Determinants and the PSE

\begin{tabular}{llll}
\hline & & PSE & SSC \\
\hline \multirow{2}{*}{ Karl Pearson Correlation (r) } & PSE & 1 & 0.491 \\
& SSC & 0.491 & 1 \\
\hline \multirow{2}{*}{$\boldsymbol{p}$-value } & PSE &. & 0.00 \\
& SSC & 0.00 &. \\
\hline
\end{tabular}

$\mathbf{N}=92, \boldsymbol{\alpha}=0.05$

The Pearson's correlation analysis between Structural Social Capital and Performance of Social Enterprise, yielded a coefficient of $r(92)=0.491, p=0.000<0.05$. This signifies that the variables have a positive relationship that is statistically significant at $5 \%$.

\subsection{Chi-Square Analysis on the Influence of Entrepreneurial Determinants on Performance of Social Enterprises}

Further analyses were conducted for confirmatory purposes using Chi-Square analysis. The chi square tests (Table 
7) results are indicated in terms of the Pearson Chi-Square Values, degrees of freedom and p-value at 5\% levels 2

of significance. Large value of $\chi$ statistics means a small probability by chance alone $(\mathrm{p}<0.05)$ hence there exist a relationship between the variables under assumption of no association.

Table 7: Chi-Square Results

\begin{tabular}{llll}
\hline Determinants & Pearson Chi-Square & Degrees of Freedom & $\boldsymbol{p}$-value \\
\hline SSC & 47.16 & 16 & 0.000 \\
\hline
\end{tabular}

The influence of Structural Social Capital on Performance of Social Enterprises yielded a $\chi(16, \mathrm{~N}=92)=47.16$, $\mathrm{p}=0.00<0.05$. This implies that the influence of structural social capital on social enterprise performance is significant at $5 \%$ levels of significance.

\subsection{Summary, Conclusion and Recommendations 4.1 Summary of findings}

From the findings, it revealed that Structural Social Capital aspects considered the vertical or linkages instrumental in operations of the enterprises. Structural social capital aspect focuses on the number or amount of direct and indirect networks. The structural or the linking social capital symbolizes the network between a community or groups in a community with institutions and groups of higher order and is therefore associated with structural social capital. Institutional ties made it easier to access information related to education and training facilities, health services, water supply and waste management among other important services to members. Similarly it considered being easy to seek information and access to business loans thus enhancing the potential of doing business among members. The collective action of social entrepreneurs in seeking solutions to the challenges was considered crucial since it makes available adequate advice from formal institutions that include Banks, credit Sacco's, and Government and which resulted to empowerment of the social entrepreneurs. Majority of the respondent indicated that the vertical associations with institutions outside the community set up were crucial in soliciting help from government officials, community leaders and financing institutions. Social enterprises were able to access information about current government and non-governmental programs that may be beneficial to the social enterprises owners and managers e.g. training. The networking established by the enterprises operators, enabled the establishment and accessibility of linkages for markets, finances, training and empowerment and suppliers. Content analysis of the structural social capital revealed that the instititutional suppor and viability strong in the form of information acquisition, partnership and financing. As for the viability of the support, in terms of presence and social transformation encountered it was considered the support to be highly viable. This shows that the social enterprises are adequately supported in terms of information, partnership and was financing.

\subsection{Conclusions}

The findings of the study depicted that Structural Social Capital had significant influence on performance of social enterprise in Nairobi City County, Kenya. Therefore the social enterprises should invest more in structural social capital. Structural social capital enhancement is critical in acquisition of partners to support the economic agenda, whereby partners will push the boundaries of what was once perceived unachievable. The social entrepreneurs needed resources from institutions e.g. training, information on market linkages, support system for technology and marketing, besides the need for funds to scale the businesses. Institutional Support Strength and Viability was found essential in acquisition of government and non government support programmes for the community social entrepreneurs should invest more in vertical and institutional linkage s for resources diversification and increase in scale of business which would increase the social value creation. The findings also subscribes to the study by (Côté \& Healy, 2001; Woolcock, 2001; Pretty, 2003) which found that social capital involves vertical interactions with individuals who are influential in positions in institutions of political or financial power and whose linkages are critical for leveraging resources accessing most needed ideas, policies from formal institutions and which are beyond the local community horizontal networks

\subsection{Recommendations}

The successful performance of social enterprises is highly influenced by utilization of social capital especially the structural social capital to achieve the value creation intended.

Social entrepreneurs need to engage deeper in structural social capital as a critical enabling factor for growth and sustainability of enterprise e.g. acquisition of finance, and procurement of other resources, this can be done by enrolling in training programmes that provide enterprise management support.

Structural social capital enhancement is critical in acquisition of partnership to foster economic goals, otherwise perceived impossible.

The effect of social capital as collateral for other resources acquisition needed to significantly influence the performance of social enterprises should be appreciated and encouraged through recognition by financing 
institutions.

Policy makers should focus on social capital forms to ensure they are scaled up in political social and economic initiatives to fast track economic development of the country as a means to for escaping the poverty cycle. From the research findings, currently there exists no policy frame work for support of socially driven enterprises.

Support systems and ecosystem should be developed, furthermore those in existence were found not to engage the small organizations with social mission calling for public institutions and government agencies to provide information and set standards of operation, campaign for change, deliver public services, promote social enterprise and mentorship.

\subsection{Areas for further Research.}

This study explored the influence of entrepreneurial determinants on the performance of social enterprises in Nairobi City County, Kenya

Social entrepreneurship is a new area of study in Kenya with scarce academic literature on history and development of social entrepreneurship, hence the need for in depth research on the subject. There is a need for an in-depth research on social capital affects the behaviour of the social entrepreneur in the Kenyan context of a developing economy faced with many social, ethnic, political challenges.

From the findings of the research social entrepreneurship seems to be growing rapidly fuelled by the endemic and ever increasing social challenges in growing population struggling with limited resources, consequently there are many unaccounted for or unregistered enterprises actively engaging in social value creation and there should be a fresh mapping for the purpose of accountability. Empirical investigation on the fast emerging social enterprises sector and its contribution to the growth the Kenyan economy should be carried out. There is a need to research on antecedent factors contribution to social enterprise emergence.

\subsection{References}

Ali.N, Saeid .N, Mohsen. S, 2012. The study of relationship between social capital and organizational citizenship behavior in Iran Carpet Joint Stock Company. International Research Journal of Applied and Basic Sciences. www.irjabs.com ISSN 2251-838X / Vol, 3 (S): 2720-2727 Science Explorer Publications.

Andrews, Rhys. 2010. “Organizational Social Capital, Structure and Performance.” Human Relations 63(5):583608.

Babbie, E. (1995). The Practice of Social Research. 7th ed. Belmont, CA: Wadsworth.

Bailey, K., 1994, Methods of Social Research, Fourth Edition, New York: The FreePress.

Basu, S. (2012).Social Capital and Social Entrepreneurship in the Third Sector. Interdisciplinary Journal Contemporary Research in Business. Vol. 4:3, 368 - 395

Bourdieu, P. 1986. "The Forms of Capital." Pp. 241-58 in Handbook of theory and research for the sociology of education, edited by J. G. Richardson. New York: Greenwood Press

Coleman, James S. 1990. Foundations of Social Theory. Cambridge: Harvard University Press.

Cote S, Healy, T. (2001) The Well-being of Nations. The role of human and social capital.

Datta, B.P. and Gailey, R. (2012). Empowering Women Through Social Entrepreneurship: Case Study of a Women's Cooperative in India. Entrepreneurship Theory and Practice. Vol. 36. (3). pp. 570- 587

Ernst (2011). Heart over Mind-An empirical analysis of social entrepreneurship intention formation on the basis of theory of planned behavior. University of Wuppertal.

Fukuyama, Francis. 1995. Trust: The Social Virtues and the Creation of Prosperity. London: Hamish Hamilton.

Gooderham, Paul N. 2007. "Enhancing Knowledge Transfer in Multinational Corporations: A Dynamic Capabilities Driven Model." Knowledge Management Research \& Practice 5(1):34-43.

Granovetter, Mark. 1985. "Economic Action and Social Structure: The Problem of Embeddedness." American Journal of Sociology 91(3):481-510.

Grootaert, Christiaan, Deepa Narayan, Veronica Nyhan Jones, and Michael Woolcock. 2003. Measuring Social Capital: An Integrated Questionnaire.

Karimzadeh, Majid, Faraz Ahmad, Bahman Karimzadeh(2013). Impact of Social Capital on Quality of Life:Evidence from India, International Journal of EconomicPractices and Theories, 3(4), 264-271.

Krishna, Anirudh and Norman Uphoff. 1999. "Mapping and Measuring Social Capital: A Conceptual and Empirical Study of Collective Action for Conserving and Developing Watersheds in Rajasthan, India." Social Capital Initiative Working Paper No. 13. Washington DC: The World Bank

Lind, D. A., Marchal, W. G., Wathen, S. A. (2008) Statistical Techniques in Business \& Economics, New York: McGraw Hill Irwin

Nahapiet, Janine and Sumantra Ghoshal. 1998. "Social Capital, Intellectual Capital, and the Organizational Advantage." Academy of Management Review 23(2):242.

Narayan, D. and L. Pritchett (1999), "Cents and Sociability: Household Income and Social Capitalin Rural 
Tanzania", Economic Development and Cultural Change, 47, 871-889.

Olabisi, S.Y., Olagbemi, A.A. \& Atere, A.A. (2011).Factors Affecting Small-Scale Enterprises Performance In Informal Economy In Lagos State Nigeria, Africa Journal of Enterprises management, 1:13, 201-212

Organisation for Economic Co-operation and Development, Paris.

Ounagh, N. and Ounagh, M. (2011), A Comparative Study of Social Capital and Quality Of Life in Delhi and Tehran, Journal of Exclusion Studies, 1:1, 19-35.

Putnam, \& Robert D. 1995. "Bowling Alone: America's Declining Social Capital." Journal of Democracy 6(1):65-78.

Putnam, Robert D. 2000. Bowling Alone: The Collapse and Revival of American Community. New York: Simon $\&$ Schuster.

Sekaran, U., \& Bougie, R. (2010). Research Methods for Business: A Skill BuildingApproach (5th edition). New Jersey: John Wiley and Sons.

Stone, Wendy and Jody Hughes. 2002. Social Capital: Empirical Meaning and Measurement Validity. Australian Institute of Family Studies.

Triola, M. F. (2008). Elementary Statistics Using the Ti-83/84 Plus Calculator (2nd edition). USA: Addison Wesley.

Woolcock, Michael and Deepa Narayan. 2000. "Social Capital: Implications for Development Theory, Research, and Policy." The World Bank Research Observer 15(2):225-49.

Woolcock, Michael. 2001. "Microenterprise and Social Capital: A Framework for Theory, Research, and Policy." The Journal of Socio-Economics 30:193-98.

World Bank. (2002). Integrated Questionnaire for the Measurement of Social Capital Available the World Bank. 